Makrufa Sh. Hajirahimova ${ }^{1}$, Aybaniz S. Aliyeva ${ }^{2}$

1,2 Institute of Information Technology ANAS, Baku, Azerbaijan

1.makrufa@ science.az, ${ }^{2}$ aybeniz63@ rambler.ru

\title{
BIG DATA INITIATIVES OF DEVELOPED COUNTRIES
}

\begin{abstract}
Big Data - regarded as a strategic resource in the fields, such as science, health, industry, and business, is increasingly attracting attention of state authorities. Currently, a number of states aim at allowing the use of large volumes of data to increase the efficiency of decision-making processes and activity of organizations, creation of new services, generation of new ideas and etc. Full support is provided for application of big data technologies and solving problems in this field at the state leveling a number of countries. Big data initiatives of some developed countries in this field are being explored. Initially, views of international organizations on "big data" are mentioned. Big data strategies of countries, such as the USA, Great Britain, France, Australia, China, South Korea, are studied. Suggestions and recommendations are developed on the formation of "big data" state policy in Azerbaijan.
\end{abstract}

Keywords: big data, big data technologies, big data analytics, big data strategy, data scientist.

\section{Introduction}

The end of the second millennium and the beginning of the third millennium is characterized by the emergence of the information society. In this society, information has become an important resource as a particular type of goods in terms of commercial, private and public interests. The increase of the information and communication tools and of the information availability in the past decade has led to an increase in data stream, and data volume has enlarged in geometric progression each year. Analysts predict that there will be no reduction in this trend in the coming years. "Big data - big today, normal tomorrow" has been recognized as a source of obvious or secret knowledge by the academic and business communities [1]. Since 2004, the emergence of the technological platforms as MapReduce, Hadoop and others, which provide real-time largescale data processing and include deeper analytical tools, has increased the value of data once more. Because, the joint analysis of structured and unstructured data, and acquisition of new knowledge and useful data out of them is very important for making new scientific discoveries, fast and accurate responding to the incidents at the public and private organizations, making reasonable decisions, as well as for national security and public health areas. In this regard, big data technologies are attracting the attention of scientific, industrial, business and other areas, including the public sector - the largest producer and consumer of data [2]. Now, many countries are stating the initiatives to benefit from the opportunities of big data in the areas, such as national security, social and economic development, health and so on. We can state that, in the future, economic and political competition among the countries will ground on the use of potential opportunities of big data. In other words, the study and application of large scale data will be necessary in order to increase the competitiveness of any country [3]. Therefore, the study of the current situation in this field and the exploration of the documents (strategy, initiative, etc.) adopted by the states is of great importance.

\section{Big data through the lens of the international organizations}

Big data is one of the key topics discussed at the international level. It is considered to be the driving force of the Information and communication technologies (ICT) sector and called "new oil". Big data is in the focus of international organizations as a resource of the strategic importance. In recent years, big data is given a high value by the international organizations, and a number of strategic plans and projects have been adopted for the use of its potential opportunities. In 2012, the World Economic Forum in Davos valued big data as a new economic asset, and released a document demonstrating its capacity for the international development [4]. 
Taking into account the technological development in the world and the volume and diversity of information rapidly growing in real time, in 2009, the United Nations initiated "Global Pulse". The initiative is a concept designed to take advantage of big data opportunities to maintain global and sustainable development, to eliminate poverty and crisis, to raise the living standards and humanitarian activity $[2,5]$. The initiative aimed at realizing the use of digital information sources, data high-speed collection and analysis technologies by the real-time decision-making bodies in order to better understand the factors affecting the formation of the vulnerable segments of population and to discover anomalies, trends and events [6]. The key issues of "Global Pulse" include: the study of innovative methods and techniques for real-time data analysis; the integration of free and open source software source technological tools for real-time data analysis and exchange of hypotheses; the development of national "Pulse Lab" global network in the country. "Putting people's voices at the development center by using big data analytics", "Data visualization and interactive mapping to support response to disease outbreak", and more than 45 similar projects have been planned to be executed within the framework of the initiative.

The report Exploring data-driven innovation as a new source of growth presented in October 2012 by the Committee for Information, Computer and Communications Policy (OECD), which mainly focuses on the representative democracy and free-market economy, surveys the potential role of data and data analysis for the formation of knowledge-based capital that is capable to stimulate the sustainable development of innovation, economy and society, and to contribute to significantly competitive supremacy [7]. The report presents the potential value of using data as a source for increasing the productivity of innovations and labor in the areas such as online advertising, public administration, healthcare, public utilities, logistics and transport.

In December 2013, by the European Commission adopted the largest research and innovation program "Horizon 2020" of the European Union (EU). About 80 billion Euros of funds is planned to be allocated for the implementation of this program, which is aimed at ensuring global competitiveness of Europe. The program defines research and innovation strategy for the successful implementation of excellent science, industrial leadership and societal challenges, including big data economy. The program allocates 120 million Euros for big data related to the study and application industry within the framework of the document. The main objective of the program is to accelerate scientific discoveries and innovations in areas such as healthcare, energy, transport, climate change, agriculture, security, management and etc. through big data and to achieve the development of the European economy manageable through data. The program is mainly targeted to maintain and develop the leading position of the EU in electronics, computing, robotics and network technologies. One of the main focuses of the program is the development and use of language technologies [8].

Within the framework of "Horizon 2020" program, more than 87 projects, including So Big Data Research Infrastructure, Education for Data Intensive Science to Open New Science Frontiers, High Performance Computing (HPC) and Big Storage: Storage-based Convergence between HPC and Cloud to handle Big Data and others have been adopted [9]. The grant Big Data Europe prepared within the program aims at accelerating the use of big data technologies in the areas, such as healthcare, agriculture, energy, climate change, social sciences, and security, in other words, developing and introducing an architecture of the infrastructure that meets the requirements of the multilingual data sets, data analytics and visualization [10].

The funding of 3.8 million Euros is allocated to the execution of the project Big Storage: Storage-based Convergence between HPC and Cloud to handle Big Data within the framework of "Horizon 2020". The main objective of this project is to conduct theoretical and fundamental studies and to improve complex infrastructure and software packages. The project is supposed to play an important role in developing researchers and planners in the international context $[9,11]$.

iKnow (Interconnect Knowledge) project adopted by the European Commission in September 2009 is aimed at deepening the researches in Europe. The EU's studies conducted 
within the framework of this project related to earthquakes, tsunami, terrorism, network and global crises is based on big data opportunities [12].

The World Bank also widely studies the big data opportunities and considers the use of these resources in many areas, such as increasing the efficiency of contributions and coordination, improving the transparency and social responsibility [13].

\section{Big data in the policy of the world countries}

Along with the international organizations, Big data have attracted the attention of many developed countries of the world. The first initiative in this field has been put forward by the United States. Later, several Western countries, including Australia, China, Japan and others, have estimated big data as a strategic resource as oil, besides, the great importance is given to the problems in this area and numerous relevant documents have been adopted.

Big Data initiative of the US. Big data has already shifted from the research and development phase to the implementation phase in the US. The US President Administration announced Big Data Research and Development Initiative in March 2012 [14]. The Initiative intended to hold complex events (conferences, forums, etc.) for the use of big data technology in the key areas of the US government policy and developing projects. In addition, 200 million USD was allocated to the relevant government agencies in order to organize and analyze large volumes of digital data. In general, the document assumes the development of 84 projects [15].

The initiative gears towards improving the new infrastructure and research methodology of the data, and fostering the competences to use them for scientific discoveries. The White House intends to use BD for the following purposes:

- developing technologies necessary for collection, storage, protection, management, analysis and share of large-scale data;

- accelerating scientific discoveries in the field of science and engineering (technology), strengthening national security, and mastering this technology to radically change education and training;

- enhancing the identification of new talents and the training of specialists for the development and use of big data technologies. The project is designed to train data scientists and engineers, in particular, analysts with high capacity in the field of data extraction from texts in any language.

According to the document, the data is to be applied in the following areas: healthcare and social protection of the population, environment and sustainable development, responding to emergencies, manufacturing, robotics and intelligent systems, cyberspace security, transport and energy, education and development areas of human resources.

To take the maximum advantage of the opportunities created by Big Data and to make efficient use of their potential, the state, industry, research institutions and non-profit organizations should act jointly for the implementation of this initiative.

As a part of the initiative, the National Science Foundation has allocated 10 million USD for the project "Expeditions in Computing" planned to be implemented at Californian universities within 5 years. The project is designed for the integration of three different approaches as machine learning, cloud computing and crowd sourcing for the data research - transformation of data into information $[14,16]$.

Within the framework of Big data initiation, the Ministry of Energy has allocated the funding of 25 million USD to the Institute of Scalable Data Management, Analysis and Visualization (SDAV) for the implementation of the project Scientific Discovery Through Advanced Computing. Under the leadership of the Lawrence Berkeley National Laboratory of the Ministry of Energy the Institute of SDAV involves the use of 6 national laboratories and the practice of 7 universities for the preparation or development of new tools to assist the researchers in data management and visualization in supercomputers $[15,17]$. 
"The Defense Advanced Research Projects Agency" (DARPA) has already started XDATA program to develop available computing technology and software tools for large-scale data analysis. The program focuses on the key issues as the expansion of scaling algorithms for data processing and the development of effective human-computer interaction tools accelerating the visualization for different purposes [15.18].

Big Data strategy of Australia. In recent years, Australian state authorities have evaluated data as a national value. Data analysis with the introduction of new technologies is believed to be contributive both for the Australian government and the Australian people. Big data have become an indispensable factor in the government policy making, the introduction of new services, and in creating opportunities for innovation.

In 2013, the Australian government adopted Australian Public Service Big Data strategy [19]. The strategy involves the projects to realize the reforms in the public service sector and to provide more effective public policy and information security of the citizens' by using capacity of large-scaled data. The main objective here is increasing the efficiency of services provided in the public sector and positioning Australia among the leading countries of the world for the use of data analysis in the field of collaboration and innovation [19]. The concept aims at the expansion of services, opportunities for new services and business partnership, improved political development and data privacy, as well as benefiting from the government support for investing in ICT sector. The development of the strategy was initially specified in the Australian Public Service Information Communication Technology Strategy 2012-2015. The main point of this conceptual document is generally defined as follows: providing better services by improving services and raising their quality; improvement of the efficiency of the governmental activity through the optimal investment and the expansion of innovation; direct participation in generating knowledge and effective cooperation. In addition, two other projects are proposed in the strategy: 1) Development of a register of information assets; 2) Monitoring of the technical development in big data analysis $[19,20]$.

Solution of these issues depends on the efficient and effective use and analysis of data following six sub-principles, which are:

- database (which is common for all) is a national wealth;

- privacy of the project;

- data completeness and transparency of the processes;

- distribution of gained experiences, resources and capabilities;

- cooperation between industry and research institutions;

- increasing public data.

Currently, the Australian Customs and Border Protection Service is taking advantage of the opportunities of big data in the identification of the suspects [21].

Big data policy of Great Britaini. Great Britain is a potential country to turn big data revolution into one of the main events of the 21 st century. Hence, this country has world-class business sectors such as aerospace, automotive, agro-technology, healthcare, media, telecommunications and others. It has huge opportunities in human resources, infrastructure and data, and the highest share in the field of the high performance computing systems in the world. It is also a world leader in data science and computer science. Special attention is paid to the development of e-infrastructure here. High performance computing, cloud computing and other modern technologies ensuring solution of very complicated and time consuming issues are the basis of e-infrastructure in Great Britain. The government allocated an investment of 158 million sterling for HPC resources in 2011 and 375 million sterling in 2012 [22].

Great Britain holds a leading position in the world for open data. Since 2010, data.gov.uk has generated more than 10,000 data sets. The world's first Open Data Institute was also established here [23]. 
In order to improve the quality of services provided in Great Britain ,in October 2012, Data Service was established by the financial support of the Economic and Social Research Council (ESRC). Data Service is a national service providing sociologists, researchers and practitioners with the access to census data, social and economic data sets funded by the state. The service combines the elements of Economic and Social Data Service established by ESRC, Secure Data Service, Census.ac.uk web-site, including the Census Programme [24]. In October 2013, additional financial support was given to Data Service by the UK government departments and other authorities for the coordination of Administrative Data Research Network (ADRN), which provides access to administrative data [20,25]. ADRN is considered to be one of the stages of big data network of ESRC, and its main function, is to ensure researchers, teachers, students, local politicians, philanthropists, and business owners with "high quality social and economic data". The government of Great Britain allocated 64 million pounds of funding for data network of ESRC to optimize the data as a resource. Various large-scale data collected by the government departments, enterprises and organizations is an important resource that can be used for the research institutions, organizations and for whole community [25].

Big Data, which has the potential to change every business sector and field of science, is one of eight major technologies (big data and energy-efficient computing, satellites and space spatial programs, robotics and autonomous systems, synthetic biology, regenerative medicine, agrarian science, most advanced materials and nanotechnology, energy and its maintenance) of Great Britain. In 2012, the government invested 189 million pounds to data centers and energy-efficient computing to solve big data issues $[22,23,26]$.

In June 2013, the British government adopted the Industrial Strategy: government and industry in the partnership (Information Economy Strategy) aimed at developing information economy. The strategy emphasizes the huge potential of big data to change all sectors of the economy, and shows the importance of e-infrastructure and scientific data to take advantage of large-scaled data. The strategy also ensures more effective use of information technology and data and provides the citizens to benefit from the digital century [23, 27]. In October 2013, as a continuation of the mentioned strategy, the government adopted the strategy Seizing the opportunity of data: A strategy for UK data Capability [22, 28]. The strategy developed with the cooperation of industry and scientific community aimed at making the UK a world leader for the use of useful information, which is extracted from data, by the citizens, business and academic circles, including public and private sectors. The strategy includes the following aspects $[22,28]$ :

- Human Capital: specialized workforce and data confident citizens;

- Available tools and infrastructure for data storage and analysis;

- Data as an enabling factor: accessibility and sharing opportunity of relevant data by consumers, business and scientific community.

To this end, the strategy is designed to take measures, such as capacity building in the business, academic and public sector; strengthening the skills targeted at schools, universities and the further education; supporting the capacity of Research and Development (R\&D) data in Great Britain.

Big data plan of France. France is an industrial country, where business, scientific inventions and entrepreneurship have developed. The smart and network technologies, software, cloud computing, big data and information security systems and so on are considered a priority in France. In this country, data have become the new economic asset of the government, enterprises, regions and cities. Since 2011, the government provided access to the public data [29].

The country pays special attention to the development of the digital economy. To this end, in February 2013, the French government adopted a plan "Digital Roadmap". The plan involved the implementation of seven project, including Big data. Within the framework of the "Programme of Investments for the Future", an investment of 11.5 million Euros has been allocated to the plan [30]. The plan incorporates three main areas: 1) capacity building of the digital economy for the younger 
generation; 2) strengthening the competitiveness of French companies at the expense of the digital economy; 3) promoting the values of the digital society and economy.

In recent years, French government increased attention to the development of policy in the field of big data. Thus, the strategic program "New Industrial France" adopted in September 2013 included Big Data as one of the main 34 largest interrelated projects of the reconstruction of French industry (medical biotechnology, digital hospital, cloud computing, online education, Nanoelectronics, the Internet of Things, contactless services, supercomputers, robots, cyber security, the plants of the future and other areas) [20.30]. Big Data plan was adopted in July 2014 as a part of this strategy. The goal of the plan is to make France a world leader in this field. The initiative covers the areas, such as building technological resource centers, to develop the trainings and startups of data scientist, and supporting scientific research [30].

The plan mainly covers three sets of activities: the development of big data ecosystem in France; initiatives in the field of big data(which includes projects in the public and private sectors); evaluation of regulations (which includes privacy rules) [20,30].

Big data strategy of Japan. Japan ranks third in the world for the size of the economy [31]. Japan has high-level ICT infrastructure and the world's leading service providers in ICT as Fujitsu, Hitachi, NTT Data and Nec. More than $86 \%$ of the population of Japan is the Internet and smartphone users, and the highest growth rate in this area around the world $[32,33]$. Big data is one of the main economic priorities for the Japanese government, and a number of strategies have been adopted by the government in this area.

In 2012, the government adopted Open Government Data Strategy in order to contribute to the transparency in Japan. The Council for Regulatory Reform initiated the establishment of the basic principles for the use of large-scaled data by the large local companies without violating the privacy laws. The Japanese government allocated 13.2 billion Japanese yen for the implementation of this strategy [34]. Furthermore, the national big data strategies the Integrated Strategy for ICT 2020 and Declaration to be the World's Most Advanced IT Nation were adopted by the government in 2012 and 2013 respectively. These strategies aimed at developing the strategy of information technology of Japan during the period of 2013-2020 through open public data and big data. The main objective is to acquire the status of a country with high standards for extensive use of big data in the information technology industry of Japan $[5,35]$. The strategy reviews the use of big data in the creation of new businesses and job creation, as well as new services in ecology, education, transport and other sectors through the cooperation with private and public sectors. The document stresses the importance of expanding the access of private sectors to the public data and supporting the creation of new business areas and services at the expense of the use of big data [35].

In June 2013, the Japanese government adopted Japan Revitalization Strategy. The strategy outlines the creation of strong infrastructure and facilities to connect to data services market and plans to make Japan the world leader in information technology [36]. The goal of the strategy is to strengthen its position as a world-leading IT nation. The government predicts the volume of data service market to reach 51 billion pounds by 2020 . Moreover, $87.5 \mathrm{mln}$ pounds have been allocated for the projects on the expansion of studies and the development of network virtualization technologies and data analysis programs and so on. Newly established technological infrastructure focuses on improving the industrial competitiveness of Japan and on the creation of new manufacturing and innovation areas [35, 36, 37].

Big Data initiatives of China. Holding a series of events associated with -Big Data Technology Conference, Big Data \& Analytics Innovation Summit, China Legal Big Data Symposium, Big Data Asia Showcase, Big Data World Forum and others in China is explained with the technological advances in this area in this country [38]. China, which has 1.2 billion mobile subscribers, possesses the world's largest mobile phone market and more than 700 million Internet users. Social media in China takes more active position. According to official estimates, more than 250 million people use social media, including 
blogs, social networks, micro-blogs and others. Non-governmental organizations estimate that this figure is close to 590 million $[38,39]$.

Increasing volume of information, including the rising number of mobile phone, social media and the Internet users in China has created favorable conditions for the use of big data in identifying problems in the country and developing the country. Now, the public sector has started exploring the potential of big data. In June 2014, the Chinese People's Political Consultative Council put forward the initiative to use the potential of big data technologies in raising the administrative capacity at the forum held by the council [20.38].

The initiative also considers the use of big data in the fields as improving the performance of public sector; developing urban transport planning; understanding the socio-economic trends; assessing the poverty; assisting e-waste disposal; and identifying hot points of pollution in urban areas. To use big data potential, first of all, it is important to create conditions to carry out joint work of public and private sectors in order to solve numerous problems (data analytics, system problems, etc.) [38].

Big data projects of South Korea. South Korea has an extensive experience in the use of the latest technology. Economic development of the country, innovation and competitive advantage is achieved through the application of these technologies. This trend is also observed in the field of big data use. As other technologies, big data have already started to play an important role in the development of South Korea. The use of Big data has attracted the attention of the scientific community, private and public institutions too. The President's Council of National ICT strategy established a working group within the framework of big data initiative in 2011. The initiative was aimed at the analysis of public big data networks and systems; the convergence of data between the public and private sectors; the diagnostic systems for open large data; the creation of the management and analytical technologies in the public and private sectors. Besides, the initiative also includes the cooperation of Big Data Strategy Center of the Agency for the National Information Society with the big data Institute, which operates under the Seoul State National University [40].

In November 2012, the National Science and Technology Commission of South Korea developed Big Data Master Plan. The plan considers the use of big data in the public policymaking, public service sector, protecting the competitiveness of small and medium enterprises, the development of research skills, and in the creation of new infrastructure. The objective of the plan is to realize the idea of Smart Nation. As part of this plan, Pilot Project for Big Data in Using Official Statistics has been established by the government [20].

South Korea is developing information systems of big database for the prediction of natural disasters based on the information obtained from various sources. The government plans to use big data for the census. In comparison with the traditional census, this is a savings of 140 million USD [41]. Due to the rapid analysis of large volumes of unstructured data obtained from Facebook, Twitter and other social networks, the growing number of suicides in South Korea in recent years is prevented [42].

\section{Recommendations regarding the use of big data technologies in Azerbaijan}

Azerbaijan is one of the countries that hold a high position for the comprehensive use of ICT in public administration [43-45]. It should be noted that Azerbaijan has already started the studies in the field of big data, which is one of the major challenges of the XXI century, and the use of this technology in some fields of activity. Thus, the volume of data collected and processed through the e-government portal is rapidly growing. It should be noted that e-government portal was founded in 2012, and it currently unites 80 organizations, delivering over 650 e-services to citizens in general, and the number of its users reached 2.5 million. And this, in turn, causes serious problems for the analytics of state data for different purposes. In order to tackle the problem, cloudbased Data Center, which is the first in the region, is ready for operation. The launch of the Data 
Center will enable the expansion of "e-Government", and the preservation of the data of both state and non-state bodies [46].

It should be noted that the Institute of Information Technology of ANAS is exploring the problems of knowledge extraction from big data sets. At the same time, AzScienceNet Data Center with the huge memory and computational resources (200 terabytes of memory, 14 Tflops computing power) is operating at the institute. . It should be noted that AzScienceNet is connecting around 4000 computers of research institutions of ANAS. The centre, which is considered to be a key infrastructural element for Big data, offers cloud services for the complex scientific issues that require large computing resources and provides storage resources for the institutes and organizations of ANAS.

Overall, the wide research and application of big data technologies and the support provided by the state to solve the problems in this area is recommended. The implementation of the following measures by the state issuggested:

1. to analyze the different situations related to the application of Big data in the country, and to identify the priority areas of this technology.

2. to develop the national big data strategy. In the course of the preparation of this strategy, a separate document or a part of the ICT strategy that is based on the experience of developed countries and suitable to the development strategy of the country can be adopted.

3. to develop e-infrastructure. The development of software and infrastructure necessary for large-scale data collection, storage, protection, management, analysis and sharing. Providing the state support to the development of high performance computing, cloud and other advanced technologies, which ensure the calculation of very complex and time consuming issues that require big memory capacity.

4. to improve the quality of services provided in the field of data in Azerbaijan.

5. to develop and support the open public network that ensures the efficient use of big data for the society, which is collected by the government departments, enterprises and organizations.

6. to accelerate the training of new talents in the development and use of big data technologies and experts and to improve the capabilities to use them for scientific discoveries. To train data scientists and engineers, and high-capacity analysts.

7. to organize the teaching of academic discipline in data scientist in higher and further education degrees, to establish technological resource centers, and to support research, and so on. 8.to coordinate and organize the joint activities of the state, industrial, academic and nonprofit organizations to take maximum advantage of big data opportunities and to effectively use its potential.

9. to develop the ecosystem of big data. To develop smart and network technologies, software, cloud computing, information security and other areas.

10. to create and improve the legal framework in regards with the introduction of Big data technologies. It includes key issues such as the provision of data storage and protection, information security, privacy of citizens and etc.

Big data technologies should be applied in the following areas: healthcare and social security of population, ensuring transparency, environment and sustainable development, response to emergencies and natural disasters, transport and energy, education and labor resource management and development, and the creation of new businesses and services.

\section{Conclusion}

The emergence of real time Big data processing and analytics technologies has enhanced the value of data. This, in turn, attracted the attention of countries to make the maximum use of data. Because, Big data analytics may play a crucial role in the solution of the problems as the prevention of the infectious diseases, terrorism, natural disasters and global risks, and in making the right decisions in health, social security and so on at the state level. Prominent international 
organizations and developed countries have adopted a number of documents in this field. Conducted studies allow us to state that these states have adopted big data strategies in various fields (scientific, social, economic, health, safety, etc.). Therefore, adopted strategies principally differ from one another.Azerbaijan is distinguished for the development rate of ICT sector, for the number of Internet and mobile users in the CIS region, and characterized by sustainable economic development. To develop the future policy and maintain the competitiveness of Azerbaijan, it is exceptionally important to use big data technologies through studying the experience of advanced countries in this field and to benefit from them. At the same time, defining the priority areas of big data technology application, developing the national big data strategy of Azerbaijan, establishing e-infrastructure, open data network and its state support, training data scientists and the adoption of the necessary legal documentation in connection with the introduction of big data technologies are of great importance.

\section{References}

1. Big data - big today, normal tomorrow, 2013, http://www.itu.int/dms_pub/itut/oth/23/01/T23010000220001PDFE.pdf

2. Alguliyev R.M., Hajirahimova M. Sh. "Big Data" phenomenon: Challenges and Opportunities // Problems of Information Technology, 2014, No2, pp. 3-16.

3. Jina X., Benjamin W. W., Chenga X., Wanga Y. Significance and Challenges of Big Data Research // Big Data Research, 2015, vol. 2, no. 2, pp. 59-64.

4. Big Data, Big Impact: New Possibilities for International Development, 2012, http://www.weforum.org/reports

5. http://www.unglobalpulse.org/about-new

6. Big data for development: challenges \& opportunities, 2012, http://www.unglobalpulse.org/projects

7. Exploring data-driven innovation as a new source of growth: mapping the policy issues raised by 'big data', 2013, http://www.oecd-ilibrary.org/science-and-technology/

8. Horizon 2020 - The EU Framework Programme for Research and Innovation 2014-2020, ec.europa.eu/programmes/horizon2020

9. http://www.cordis.europa.eu/project/rcn/193971_en.html

10. http://www.big-data-europe.eu/big-data-europe-project-launch

11. http://horizon2020projects.com/h2020-project-centres-on-dealing-with-big-data

12. KNOW (Interconnecting knowledge for the early identification of issues, events and developments) project, 2011, http://cordis.europa.eu/result/rcn/54661_en.html

13. Big Data in Action for Development, 2014,http://www.data.worldbank.org

14. Big data is a big deal, 2012,http://www.whitehouse.gov/blog/2012/03/29/

15. https://www.whitehouse.gov/big_data_fact_sheet_final_1.pdf

16. http://www.nsf.gov/news/news_summ.jsp?cntn_id=12360710

17. http://www.science.energy.gov/news/

18. http://www.darpa.mil/program/xdata

19. Australian Pubic Service Big Data Strategy,2013, http://www.finance.gov.au

20. Lammerant H., Galetta A., Paul De Hert, Bigagli L., Mazzetti P., Grumbach S. Big Data Policies BYTE project, 2014,www.byte-project.eu

21. http://www.cio.com.au/article/524794/

22. Seizing the data opportunity. A strategy for UK data capability, https://www.gov.uk/

23. Industrial Strategy: government and industry in partnership, https://www.gov.uk/

24. http://www.statslife.org.uk/features/22-introducing-the-uk-data-service.

25. UK Data Service-http://ukdataservice.ac.uk

26. https://www.gov.uk/government/speeches/eight-great-technologies

27. https://www.gov.uk/government/publications/information-economy-strategy 
28. https://www.gov.uk/government/publications/uk-data-capability-strategy

29. http://s244543015.onlinehome.fr/2014/11/clerc_big-data-icci-2014.pdf

30. The new face of industry in France, http://www.entreprises.gouv.fr/

31. World Bank: India Overtakes Japan as World's Third Largest Economy, http://thediplomat.com/2014/05/

32. Japan: Big Data For A Bigger Economy, 2013, http://opentoexport.com/

33. http://www.internetlivestats.com/internet-users/japan/

34. Open Government Data Strategy, 2012 http://japan.kantei.go.jp

35. Declaration to be the world's most advanced IT nationt, 2013, http://japan.kantei.go.jp/policy/it/2013/0614_declaration.pdf

36. New Growth Strategy: The Formulation of "Japan Revitalisation Strategy-Japan is Back", 2013, //http://japan.kantei.go.jp

37. https://www.kantei.go.jp/jp/singi/keizaisaisei/pdf/en_saikou_jpn_hon.pdf

38. Jackie Hoi-Wai C. Big Data for Development in China : UNDP China Working Paper, 2014, http://www.cn.undp.org/

39. http://www.internetlivestats.com/internet-users/china/

40. 40. Jung S. Open Source Technologies for the World of Big Data, 2015, http://www.koreafocus.or.kr/design2/layout/content_print.asp?group_id=104534

41. Adarsh D., Bruno S., Rade N. Korea shows how to use Big Data for development, 2015, http://blogs.worldbank.org/

42. Song T.M., Ryu S. Big Data Analysis Framework for Healthcare and Social Sectors in Korea // Journal Healthcare Information Research, 2015, vol. 21, no. 1, pp. 3-9.

43. National Strategy on Information and Communication Technologies for the development of the Republic of Azerbaijan (2003-2012), 17 February, 2003, http://www.mincom.gov.az/assets/Uploads/KTMilliStrategiya3.doc.

44. "Azerbaijan 2020: vision to future" Development concept, 29December, 2012, http://e-qanun.gov.az/framework/25029

45. National Strategy on the Development of Information Society in Azerbaijan for 2014-2020. 2April, 2014, http://president.az/articles/11312

46. E-Government Bulletin, e-Government Portal, Bulletin No36, 2015, https://www.e-gov.az 